\title{
Study on the Batik Patterns and Crafts of the Miao Costumes in Northwestern
}

\section{Guizhou Province}

\author{
Hong Bo \\ Dean of Fashion Design Department \\ Polus International College \\ Sichuan Chengdu, 610103, China
}

\begin{abstract}
Zhijin, Nayong of Bijie city and Suoga Town of Liuzhi Special Zone and so on are the most representative districts for the culture of Miao Costumes in the northwestern Guizhou. The complex and various crafts, fine and sophisticated ornamentation and the mysterious patterns on the Miao Costumes all reflect the marvelous artistic glamour and the profound national culture heritage of the Miao Costumes. The essence of the traditional culture should be maintained so as to dig out its value which can be combined with the current aesthetic orientation and living style to guarantee the existence and sustainable development in the future.
\end{abstract}

Key words-Miao Costumes in the northwestern Guizhou; culture of costumes; Batik Patterns; the characteristics of crafts

I. General introduction to the culture of the Miao Costumes in northwestern Guizhou province

Zhijin, Nayong of Bijie city and Suoga Town of Liuzhi Special Zone and so on are the most representative districts for the culture of Miao Costumes in the northwestern Guizhou (briefly referred to as Qian) and the types of clothing are as many as 25 which is quite abundant. For a long time, the embroidery, batik, hemp fabric and other crafts of costumes are followed and inherited with the long history of farming culture from one generation to the next generation, during which different branches have different manifestations. The complex and various crafts, fine and sophisticated ornamentation and the mysterious patterns on the Miao
Costumes all reflect the marvelous artistic glamour and the profound national culture heritage of the Miao Costumes.

The Miao Costumes of northwestern Guizhou can be divided into women's dress, men's dress, sacrificial garment etc, in which the women's dress is of unique features and can reflect the basic characteristics of Miao costumes; while the sacrificia garment is only worn during the sacrifice which reflects the unique features of the sacrifice culture of Miao but it is not universal and representative; the men's dress, however, has been greatly out of use.

\section{The features of the Miao costumes in different districts} of northwestern Guizhou

1. The features of the costumes (Waishumiao) in Zhijin County of Bijie city

The decorative patterns of the Zhijin's costumes are highly geometrized and are full of patterns which are mainly birds, butterflies, bats, fishes, pomegranate, flowers and grass that are demonstrated by batiks. The decorative patterns are mainly used for clothes, corset, hats, bags, pillow towels, blankets etc. Women are often wearing short embroidery blouses with side opening and cross collar and the front swing and back swing of the clothes are often two layers. And they often wear long dress whose perimeter can reach five to six meters, which is pleated while dressing and the places for pleating are different in different districts. The materials for the clothes are often linen or fine cloth while they often wear clothes by velvet or satin during dressing up. Batik, embroidery, pester embroider, marquetry are often mixed for the crafts of costumes and red, 
yellow, purple and green are the commonly-used colors for the patterns. The patterns are mainly cloud pattern or water pattern, and sometimes, straight curve patterns or finely-divided flowers or grass patterns are used which is lovely and natural.

\section{Characteristics of the costumes culture (Changjiaomiao)} in Suoga town in Liuzhi special zone

The blouse for the women's dress are often double-breasted style that reaches the stomach in the front swing and reach the knee in the back swing, which is quite similar to the swallow-tailed coat and the difference lies in that the back swing is flat swing. The cloth used for the cloth is often 3.3 meter. The collar is cross which is together with the edge flaperon. The sleeves are often by batik or coloring. The dress is flounced and can use 6.6 meter's cloth which is as long as 0.8 meter. The upper part of the dress is by batik while the lower part is by cross-stitch which varies in geometry patterns. When wearing the dress, there is lace handkerchief of white cloth collocated around the waist and the front is black wool corset that is similar to round handbag that can store articles or can warm the hands. The techniques for the decoration contain batik, coloring and cross-stitching. The front and the back are often coloring or embroidery while the patterns for the lower part of the back and the collar are often cross-stitch or batik or coloring that varies. The colors used for cross-stitch are mainly red that combines with white, blue or yellow which is not in sharp contrast. The craft for cross-stitch are wonderful. The patterns for coloring are often round flowers that are constant in all sides, flowers of the cloud-shapes or flowers of squares. The composition technique for constant combination is the dominant decoration techniques in Miao nationality.

\section{The batik patterns and craftsmanship of different districts in northwestern Guizhou Province}

\section{Batik patterns}

The batik patterns for the Miao nationality in northwestern Guizhou are mainly geometry patterns in which some are the deviations of the natural patterns and the butterflies patterns are the most commonly-used. The natural patterns are often used for small batik while the bird patterns are most commonly-used and the pictures are spacious. There is no ground sample for batik and the inheritance for the traditional samples is by memory. No other tools or paper-cuts are used during waxing and it is only by hand-drawing, which can really be called the round of square can be formed without certain restricts. The people who are good at batik often boast that the line and the round they draw can be measured by ruler and compass and there would be no mistake. The cord design of the patterns in Xiaotuoluo town and the Wanzizhai districts of Nayong town in Zhijin city can be as slim as hair which is quite marvelous. The batik for the Miao costumes in Suoga town of Liuzhi is unique and there is not big flower but geometry fine flowers by drawing dots in the small grids.

(1). The batik patterns (Waishumiao) in Zhijin county of Bijie city

Features of the patterns: famous for its delicacy that has the origin of the batik and the beauty of elegance. The products of batik is very delicate; the pictures are full; the elements for the patterns are sample that are mainly geometric spiral patterns in which some are the deviations for the natural patterns, such as the various patterns that symbolize the fish, birds, flowers and grass, countryside, three migrations of the Miao in which the butterflies patterns are the most commonly-used. The natural patterns are often used in the small batik, and the bird patterns are commonly-used. The images are lovely, fluent and the structures of the patterns are often crossed and seamless. The delicate and complex line are combined with evenly thick lines, which can form sharp contrast and the moving is combined with the quite. Sometimes, it is dotted by embroidery by bright red, yellow, blue silk thread that weaves radial flower patterns. Only by several threads, it is full of glamour that is contrasted with blue spiral curve, which is similar to the magnificent and magical universe.

(2). The batik patterns in Xiaotuoluo town in Zhijin county of Bijie city

Features of the patterns: the patterns of the Xiaotuoluo town in Zhijin county are exquisite and beautiful and the scattered patterns are the most commonly-used. The proper-used colors are full of layering. Apart from deep blue and light blue, sometimes, red or blue embroidery are dotted in the pistils of the main parts of the patterns. The cockscomb and the mitrephora thorelii are the representatives of the patterns and 
the spiral patterns and ripple patterns are often used as well and constant composition are commonly used. The waxing often uses paraffin instead of beewax due to the delicate of the line that paraffix draws which is unlikely to crack. The batik of Xiaotuoluo is quite delicate that is once called "the most delicate batik in the earth" by the experts.

(3). The batik patterns (Changjiaomiao) in Suoga town of Liuzhi

Features of the patterns: the Changjiaomiao are often batik or coloring whose patterns are often round flowers that are constant in all sides, flowers of the cloud-shapes or flowers of squares and the sleeves are often batik or coloring. The patterns are inherited from generation to generation and there is little change. Some patterns are memorial and imparted to many generations that cannot abandon or change. The commonly-used ones are half-moon, thick curve, long straight, irregular grids, thick cross, the lights of sun, small dots and thick circles etc which are classic, vigorous, pure and rough. They are often waxed into black or deep blue ground with light blue or white flowers and there is little resistdye colors.

\section{(4). Batik patterns in Anshun}

Features of the patterns: the traditional patterns for the batik in Anshun are mainly two types, namely natural patterns that are from flowers, birds, insects, fishes and other natural species that are exaggeratedly selected and abandoned and geometric patterns that are even and balanced in all sides, the bilateral symmetry, the various in point, line to plan and the distinction in primary and secondary that pursues the unification of the integrated effects. The commonly-seen are spiral, dots, patterns of flowers and leaves, whose structure is strict in symmetry and unified. Some patterns are historical, like armor or Chinese characteristic that are free or abstract, wild and open. They are in constant symmetry and are unsophisticated and elegance. The clothes for the batik are often used as blouses, dress (sleeves, placket, back and foot of the blouse), corset, blanket, fan, edge of the bed-curtain, handbag and hats. Batik is the most popular among the women in Miao and Bouyei nationality in Anshun.

\section{Materials for batik}

(1) Tools for batik: copper knife (waxing knife), porcelain bowl, basin, spicule, cereal straw, dye vat etc.
(2) Backing material for waxing: natural cotton, fabric are often applied and the most ancient poplin is used as well. The backing color is purplish blue and the color of the pattern after waxing are blue and white. The composition is exquisite and the lines are clear which makes the white lines visible and demonstrates profound conception by simple pictures.

(3) Dye for waxing: made by the herb indigo and several herbal medicine of the local place and the most commonly-used are natural indigo.

(4) The resist agents of waxing: mainly yellow wax (beewax), sometimes mixed with white wax.

\section{Craftsmanship}

(1) The craftsmanship of the batik (Waishumiao) in Xiaotuoluo town of Zhijin county of Bijie city.

Features of craftsmanship:

The lines of the batik are mainly exquisite, in symmetry and the color batiks are the most famous. The composition of the Miao batik in the west of Zhijin are rough and vibrant while the Miao batik in the southeast district are fine and exquisite and the lines of the pattern are delicate, elegant which can be called breathtaking.

Another type of the batik in Xiaotuoluo town is dotted by embroidery on the batik cloth, namely using the red and yellow silk thread to embroidering radial patterns in the left circles which is contrasted with the blue spiral curves.

The process:

Heat the wax knife on the oil lamp and insert into a blue wax, therefore the wax knife is full of melting wax, which can be used to decorate the fine patterns.

The patterns are remained in the brains of the craftsman which is without draft. The wax is left on one side of the table without melting. The blue wax are recycled by the old wax used for many times which is clear when drawing delicate lines. After dewaxing, the blue would not contaminate the cloth.

The postures for holding the knife is with strict rules which is not to slip like holding pencil but to hold flat the knife back while the point of the knife is in vertical with the cloth, hence the fluid of the wax can fluently reach the point of the knife.

Positioning by nail before drawing, carve traces lightly on the meridian and parallel and then draw along with the groove of 
the wax knife, and cut the uneven place by nails.

Even and thick straight lines are around the delicate curves which forms sharp contrast. The combination of the moving and the silent can complement each other.

(2) The craftsmanship of the batik (Changjiaomiao) in Suoga town of Liuzhi special zone

Features of the crafts: the batik of Changjiaomiao is full and the cloth after dyeing is more white than blue. The effects of overall composition is to draw the outlines of small geometry patterns by delicate blue thread and leave some blue plane to adjust the hues properly. Though the basic elements are simple, it is not simple by smart collocation. The process: filtering the water by the ash to soaking native cloth so as to get rid of the lipid in the fiber to make it easy to wax and color. Then put proper beewax into the China bowl and place the bow on the hot ash, by heating, the wax is melt into fluid and the can dip the wax by the wax knife on the cloth. And soak the cloth with waxing colors wet and place it in the indigo dye vats for many times. After ensuring the cloth is well-dyed, then the cloth can be taken to wash along the river so that the water can wash away the surface dyeing and boil it in the water of the pot to make the melting beewax floating over the water and recycle the beewax for the future. The cloth after the melting of the wax takes the shape of white patterns, and then repeatedly washes the batik to wash away all the remained beewax. Then finished.

(3) The craftsmanship in the batik of Anshun

Features of the crafts: the batik in Anshun district remains the rare color batik of traditional batik. By combining the many plants dyes and the indigo, there is sharp contrast of colors that manifests the effects similar to embroidery. It is liked to paint red and yellow on the basis of white and blue which is called "pen color". The ancient method is to crushing down the bayberry juice and the yellow is the gardenia so as to soak in water. The combination of the red, yellow and indigo would form some middle colors, such as grass green, ocher. By applying the characteristic that the indigo can deepen by multiple dyeing, many batik products realize the varying in colors by double dyeing or multiple dyeing. The mysterious ice pattern makes the batik full of abstract conception.

The process:
Method 1: Waxing on the white cloth. Soaking and dyeing to get the light blue without dedyeing. Then rewax the light blue to form the patterns between the light blue and white part. And then soak again to form deep blue. After dewaxing, it forms the waxing cloth with abundant layers of colors, such as white, light yellow and deep blue. And the layers can be increased according to preference.

Method 2: Dye the white cloth into blue and wax flowers on the blue cloth. And then by indigo, the finished products are full of blue patterns, soft and reserved batik on the blue cloth. The patterns are often abstract variations of flowers, leaves, fishes and birds which deviated from universally-seen flowers and grass. The lines are like the weaves of the sea, which is elegant as float clouding and lively as cursive scripts and full of the passion of leafs, in which the most representative is the bougainvillea flower that is an ancient pattern handed down for a long time.

\section{The great values and the difficulty it faces of the Miao Costumes culture in northwestern Guizhou}

\section{The decrease of national features of the traditional Miao costumes}

The coexistence of culture ecology and culture is a necessary phenomenon. With the development of the social economy and the drastic changes of ecological environment, the traditional Miao costume cultures are facing with decrease and it is rapidly assimilated by the mainstream culture so the national features of the traditional costumes are greatly weakened. Take the northwestern Guizhou as an example, people wear the same clothes as Han nationality and speak Putonghua and the traditional Miao costumes can only be seen on the traditional holidays. The traditional batik craftsmanship can only be skillfully used by minority of the old Miao. With the development of touristic economy, the traditional costumes are more likely to be secular which will accelerate the weakening of the traditional Miao costumes.

\section{The craftsmanship of the traditional Miao Costumes is nearly failed to handed down}

The traditional Miao costumes are made by weaving, embroidery, batik, silver production and many other skillful productions. With the development of economy and the 
changes of people's habits, people pay more attention to the practicality and culture functions of the Miao costumes and the craftsmanship of the costumes that waste time and energy are gradually weakened. The market oriented by farming economy that the traditional skills affiliate gradually degenerated. Take the Kaili City as an example, when women takes the traditional costumes handed over by their ancestors, they would exclaim the exquisite of the embroidery crafts and the skillful of the crafts of their ancestor. The generation with the skillful crafts are aging while the new generation knows little about the crafts, hence there is lack of successor.

3. The influence of different degrees of economic development on the inheritance of the Miao costumes

By the survey and observation of some districts in the northwest and southeast Guizhou, it is inspired by the different influence of different degrees of economic development on the inheritance of the culture. In areas where the economy develops faster, the inheritance of the national culture is excellent; while in areas where the economy development relatively falls behind, people pay much more attention to their living and ignore the developments of national culture.

\section{Conclusions}

With the development of times, the vitality of the nation is in constant rebirth. The protection and the inheritance of the
Miao costumes, especially protection and inheritance of the batik, embroidery, weaving and the folk crafts with the features of Miao nationality, do not equal to the simple imitation and copy, close, total restriction and isolated preservation. It is not all that placing the Miao costumes in the Museum for eternality or enjoy but to nourish, promote, cultivate and refine the essence of traditional culture to make it growing and development and dig out the values of the culture relics of the Miao costumes. By combined and applied with the current aesthetic orientation and living styles, the Miao's costumes can survive and maintain sustainable development in the future.

\section{REFERENCE:}

[1] Yang Zhengwen. Culture of Miao Costumes[M]. Guiyang:Guizhou Press, 1998

[2] Su Rina. Costumes and Folk Culture of Minority[M]. Beijing:China Society Press, 2006

[3]Wang Tielan. Festivals and Costumes of the Minor nationalities of Guizhou [M]. Beijing:China Travel \& Tourism Press, 2006

[4] Wang Yongqiang et al. Classic Book of the Culture History of the Minority in China[M]. Nanning:Guangxi Education Press, 1999 